Louisiana State University

LSU Digital Commons

$12-1-2007$

\title{
Shared parasitoids in a metacommunity: Indirect interactions inhibit herbivore membership in local communities
}

James T. Cronin

Louisiana State University

Follow this and additional works at: https://digitalcommons.Isu.edu/biosci_pubs

\section{Recommended Citation}

Cronin, J. (2007). Shared parasitoids in a metacommunity: Indirect interactions inhibit herbivore membership in local communities. Ecology, 88 (12), 2977-2990. https://doi.org/10.1890/07-0253.1 


\title{
SHARED PARASITOIDS IN A METACOMMUNITY: INDIRECT INTERACTIONS INHIBIT HERBIVORE MEMBERSHIP IN LOCAL COMMUNITIES
}

\author{
JAMES T. CRONIN ${ }^{1}$ \\ Department of Biological Sciences, Louisiana State University, Baton Rouge, Louisiana 70803-1715 USA
}

\begin{abstract}
The interaction between species, mediated by a shared natural enemy (i.e., apparent competition), has been the subject of much theoretical and empirical investigation. However, we lack field experiments that assess the importance of apparent competition to metacommunity structure. Here, I conducted a series of field experiments to test whether apparent competition, mediated by shared egg parasitoids (Anagrus nigriventris and A. columbi), occurs between two abundant planthopper species (Delphacodes scolochloa and Prokelisia crocea) of the North American Great Plains. The two planthoppers feed on different plant species within prairie potholes (wet depressions) and, thus, do not interact directly. At the scale of individual potholes, a five-fold pulse increase in D. scolochloa density (relative to control potholes) resulted in a steady decline in $P$. crocea density over two generations. As expected in cases of apparent competition, $P$. crocea eggs in these potholes suffered twice the level of parasitism as $P$. crocea eggs in control potholes. In contrast, a sixfold increase in $P$. crocea density had no effect on $D$. scolochloa density or parasitism in those potholes. The superiority of $D$. scolochloa over $P$. crocea likely can be attributed to a larger source population size, greater amount of host habitat, and/or the presence of a phenological refuge from parasitism for D. scolochloa. In another experiment, in which small populations of $P$. crocea were established either in close proximity to $D$. scolochloa or in isolation, I found that the likelihood of $P$. crocea persistence was $36 \%$ lower in the former than the latter populations. This difference was attributable to very high rates of parasitism of $P$. crocea when adjacent to $D$. scolochloa. These two experiments provide clear evidence that the two planthopper species engage in apparent competition and that the shared parasitoids may play a significant role in limiting membership in a local community. Based on these findings, I argue that metacommunity studies must be broadened to include higher trophic levels.
\end{abstract}

Key words: Anagrus columbi; Anagrus nigriventris; apparent competition; Delphacodes scolochloa; local extinction; metacommunity; prairie potholes; Prokelisia crocea; shared parasitoid.

\section{INTRODUCTION}

Ecological communities are replete with indirect interactions, one of the most common being apparent competition (Holt 1977, Holt and Lawton 1994, Wootton 1994, Chaneton and Bonsall 2000). In apparent competition, one species negatively affects the population growth rate or abundance of the other species through the action of a shared natural enemy, and this can occur whether or not the two species share a limiting resource. It has been suggested that apparent competition is more pervasive in structuring ecological communities than interspecific resource competition, especially for assemblages of herbivores (Holt and Lawton 1993). Of the empirical studies reviewed by Chaneton and Bonsall (2000), over 75\% exhibited evidence of apparent competition. For the majority of those supporting studies, interactions between prey

Manuscript received 15 February 2007; revised 24 April 2007; accepted 26 April 2007. Corresponding Editor: W. E. Snyder.

${ }^{1}$ E-mail: jcronin@1su.edu species were asymmetric (see also Brassil and Abrams 2004, Hambäck et al. 2006, van Veen et al. 2006).

Based on the simplest theoretical models, two species sharing the same natural enemy cannot coexist together; much the same as two species sharing the same limiting resource cannot coexist (Nicholson and Bailey 1935, Holt 1977, Holt and Lawton 1994). Recently, theoreticians have examined apparent competition in the context of spatially subdivided communities (i.e., metacommunities). All studies have emphasized the importance of predator or prey dispersal to prey coexistence. In a simple two-patch metacommunity model, Holt (1997) found that if prey species occupy mutually exclusive habitats, prey coexistence is possible when the predator exhibits little cross-habitat colonization (see also Holt and Hoopes 2004). Using a coupledmap lattice model with neighborhood dispersal, Comins and Hassell (1996) and Bonsall and Hassell (2000) determined that coexistence was possible if there was a trade-off between dispersal ability and competitive ability (e.g., the inferior prey is a fugitive species [Horn and MacArthur 1972, Nee and May 1992]), or 
surprisingly, if the inferior prey was much less dispersive than the superior prey (see also King and Hastings 2003). In this latter case, the inferior prey gets left behind by traveling waves of parasitoids tracking the superior prey in space.

Very few experimental studies have examined the role of apparent competition in allowing/limiting species membership in local communities of a larger metacommunity (Morris et al. 2005). Using an elegant but simple laboratory system, Bonsall and Hassell (1997, 1998) found that the ichneumonid parasitoid Venturia canescens could persist for long periods of time with either of two moth species (Plodia interpunctella and Ephastia kuehniella) in isolated arenas. However, when the parasitoid was allowed to move freely between separate host arenas, E. kuehniella was driven extinct. This experiment supports the prediction from Holt's (1997) two-patch model that limited predator movement between prey-exclusive habitats is necessary for coexistence. In comparable laboratory system involving bruchid beetles and a shared parasitoid, Bonsall et al. (2005) found that multispecies persistence time increased as the number of patches increased and as the rate of dispersal decreased. In one of the very few experiments that have been conducted in real subdivided landscapes, van Nouhuys and Hanski (2000) found evidence of apparent competition involving a shared hyperparasitoid of two primary parasitoids. One of the primary parasitoids, Cotesia melitaearum, is a specialist of the Glanville fritillary butterfly (Melitaea cinxia). Following the experimental addition of a novel generalist parasitoid ( $C$. glomerata) to local butterfly patches, $C$. melitaearum densities declined (to zero in two of three cases).

Additional field studies are needed to better elucidate the role of apparent competition in structuring local communities (van Veen et al. 2006). For example, with few exceptions, we lack experimental evidence that apparent competition can cause the extinction of a species at the patch scale (but see also Zwölfer 1979, Müller and Godfray 1999, van Nouhuys and Hanski 2000). Given that apparent competition is thought to be very common (as already discussed), it is imperative that we study its effects in a metacommunity context.

Here, I conducted a series of field experiments to test whether apparent competition, mediated by shared egg parasitoids (Anagrus nigriventris and A. columbi), occurs between two abundant planthopper species (Delphacodes scolochloa and Prokelisia crocea; Hemiptera: Delphacidae) that reside among wet depressions (potholes) of the North American Great Plains. The two planthopper species are specialists of different host plants, negating the possibility of interspecific competition for resources. By manipulating the local abundance of both species at the patch level (potholes), I tested whether these two planthopper species interacted indirectly through shared parasitoids, and if the interaction was symmetric. In a subsequent experiment,
I tested the hypothesis that the presence of a superior apparent competitor can reduce the density and likelihood of persistence of an inferior apparent competitor within the local community. For this experiment, I monitored the fates of experimental populations of $P$. crocea established adjacent to, or in isolation from, D. scolochloa. Finally, I examined possible mechanisms leading to the dominance of one apparent competitor over the other (e.g., phenological match between planthopper and parasitoids, host preference/suitability) and the regional coexistence of the two species (trade-offs between dispersal and fecundity).

\section{Methods \\ Study system}

The prairie pothole region of northeastern North Dakota (Petersburg; 48 $1^{\prime} 15^{\prime \prime} \mathrm{N}, 98^{\circ} 7^{\prime} 20^{\prime \prime} \mathrm{W}$ ) is a formerly glaciated area characterized by numerous seasonal and permanent ponds or potholes (van der Valk 1989). A dominant wetland plant bordering these potholes is the native grass Scolochloa festucacea (Willd.) Link (sprangletop). Sprangletop has a circumpolar distribution and in North America ranges from northern Iowa and Nebraska to southcentral Canada and west to Oregon (Gould 1968). It often forms pure stands that encircle the pothole margins (Smith 1973, Cronin and Wilson 2007). Behind and contiguous with sprangletop (at higher elevation), one can find smaller, monospecific patches of prairie cordgrass (Spartina pectinata Link; see Plate 1). S. pectinata, is a common native plant species of hydric grasslands of the North American Great Plains (Hitchcock 1963). Other common hydrophytes associated with potholes are Typha spp., Phragmites australis (Cav.) Trin, Carex sp., and Scirpus sp.

The planthoppers Delphacodes scolochloa Cronin and Wilson and Prokelisia crocea (van Duzee) (Hemiptera: Delphacidae) are the dominant herbivores of sprangletop and cordgrass, respectively (Holder and Wilson 1992, Cronin 2003a, Cronin and Wilson 2007). Both species are strict specialists of their respective host plants, but otherwise are very similar in morphology, biology, phenology, and natural enemies (Holder and Wilson 1992, Cronin 2003a, Cronin and Wilson 2007). Planthoppers overwinter as nymphs in the senescent leaf sheaths or surrounding thatch. D. scolochloa nymphs emerge and begin feeding in early May and reach peak adult densities at the end of May. A second generation follows, with maximal adult densities occurring in the middle of July. P. crocea also has two generations per year and life stages of both species broadly overlap. Both planthopper species are wing dimorphic, but female $D$. scolochloa and female $P$. crocea are predominantly brachypterous and macropterous, respectively. Males of both species are predominantly macropterous.

Eggs are inserted beneath the leaf ( $P$. crocea) or stem (D. scolochloa) epidermis. In the pothole region, the two 
species share the same egg parasitoids (Cronin and Wilson 2007). Anagrus nigriventris (Hymenoptera: Mymaridae) is the dominant egg parasitoid accounting for $92 \%$ of the parasitized hosts. A. columbi, which is the only species found attacking $P$. crocea $60 \mathrm{~km}$ east in tall grass prairie habitat (Cronin 2003b), accounts for the remainder of the parasitized host eggs in the pothole region. Late-instar nymphs and adults of both planthopper species also appear to share the same undescribed dryinid parasitoid. The proportion of hosts parasitized is $<3 \%$ for each planthopper species (Cronin 2003b, Cronin and Wilson 2007).

\section{Planthopper and parasitoid census}

D. scolochloa and P. crocea adult and egg densities, Anagrus spp. density, and egg parasitism of each planthopper species were surveyed over six generations (1998-2000) from the margins of eight permanent ponds near Petersburg, North Dakota, USA. Ponds were located either in U.S. Fisheries and Wildlife Waterfowl Production Areas (Sites 100, 109) or on private land registered with the Conservation Reserve Program, United States Department of Agriculture, Natural Resources Conservation Program (Sites N29-1, N29-2, ..., N29-6). Ponds were selected that supported patches of both sprangletop and cordgrass. The minimum distance between ponds was $72 \mathrm{~m}$, which is quite far relative to the dispersal ability of the planthoppers and parasitoids (Cronin 2003a, b; Cronin and Haynes 2004; J. T. Cronin, unpublished data). Sprangletop was the dominant vegetation along pond margins, having a mean area of coverage $( \pm \mathrm{SE})$ of $1045 \pm 261 \mathrm{~m}^{2}$ (range: $227-2540 \mathrm{~m}^{2}$ ). Cordgrass accounted for $13.5 \% \pm 1.1 \%$ of the total area covered by the two host-plant species.

Adult planthoppers were censused with a sweepnet at two-week intervals starting shortly after spring thaw and ending in mid-September when sprangletop and cordgrass had completely senesced. Three sets of 10 sweeps each were conducted per host plant and pond. Sweep samples were transported on ice to the laboratory and planthoppers were inspected to determine species, sex and stage (nymph or adult). Census of adult Anagrus was conducted using yellow sticky traps $(8 \times 13 \mathrm{~cm}$ Dayglo Saturn yellow index cards [Essette Corporation, Garden City, New York, USA] coated with Tanglefoot [Tanglefoot Company, Grand Rapids, Michigan, USA]) attached to the tops of $0.5 \mathrm{~m}$ tall PVC poles (see also Cronin $2003 b, c)$. At each pond, two permanent trap stations were established per host-plant habitat. Traps were collected and replaced at intervals concurrent with the planthopper census. Female Anagrus parasitoids were counted per trap using a dissecting microscope. Because of the difficulty in distinguishing between $A$. nigriventris and $A$. columbi from trap samples, they were pooled and referred to hereafter as Anagrus.

The biweekly survey of adult planthopper and Anagrus densities was used to examine phenological differences in the occurrence of these life stages. Both planthopper species have a very short time lag between adult eclosion and the onset of egg laying (usually $<1 \mathrm{~d}$ [Cronin 2003a, Cronin and Wilson 2007]). Therefore, egg-laying coincides almost exactly with the occurrence of adult planthoppers. Eggs of both planthopper species take approximately two weeks to develop, but only those 3-10 days old are successfully parasitized (Cronin $2003 b$; J. T. Cronin, unpublished data). A good phenological match between adult planthoppers and short-lived Anagrus species (probably $<3$ d [Cronin and Strong 1990, Cronin 2003b]) would be a peak in parasitoid abundance that lags only a few days to a week behind its host.

Census of planthopper eggs and parasitism was conducted after the planthopper eggs had hatched and parasitoid adults emerged. At these times, planthopperinfested leaves or stems possessed a complete record of planthopper eggs laid and parasitism, but no live insects (Cronin 2003a, b). For each pond and host plant species, a $25 \times 25 \mathrm{~cm}$ sampling frame was haphazardly placed at five locations and within each frame I counted the number of infested and uninfested ramets (planthopper oviposition scars are easily visible at this time). I collected a maximum of 40 infested ramets from the five sampling frames. Leaves for P. crocea and stems for D. scolochloa were dissected to determine the number of unparasitized and parasitized hosts per ramet (easily determined from the shape of the exit hole in the remaining planthopper egg chorions).

Differences in eggs per square meter, number of eggs parasitized per square meter, and proportion of eggs parasitized between $D$. scolochloa and $P$. crocea were assessed using separate paired $t$ tests. The mean per generation for each species constituted the pair in the analyses ( $n=6$ generations). To normalize distributions and homogenize variances, densities and proportions parasitized were natural-log- and arcsine square-root transformed, respectively, prior to the analyses. There were too few generations to provide powerful tests of the temporal relationships between $D$. scolochloa and $P$. crocea densities and proportions parasitized.

\section{Apparent competition experiment}

I conducted a planthopper species addition/removal experiment in small potholes to assess whether egg parasitoids mediate interactions between $D$. scolochloa and $P$. crocea. Fourteen potholes were selected from Conservation Reserve Program land in Petersburg, North Dakota that were small in size $\left(19.9 \pm 1.9 \mathrm{~m}^{2}\right.$ of open water; range, 9.6-31.6 $\mathrm{m}^{2}$ ), bordered by sprangletop and cordgrass, inhabited by both species of planthopper, and isolated from other potholes by $\geq 75$ $\mathrm{m}$. In the spring of 1998 , the area covered by each plant species $\left(\mathrm{m}^{2}\right)$ was determined using a tape measure. Sprangletop was the dominant species, comprising $75 \pm$ $3 \%$ of the area occupied by both host-plant species.

Potholes were assigned at random to one of four treatments: (1) removal of D. scolochloa (Ds-; $n=4$ 
potholes), (2) addition of D. scolochloa (Ds+, $n=3$ potholes), (3) addition of $P$. crocea ( $\mathrm{Pc}+, n=3$ potholes), and (4) unmanipulated control ( $n=4$ potholes). I elected not to use a $P$. crocea removal treatment because the area of coverage of cordgrass relative to sprangletop was so small. I surmised that the removal of P. crocea would only account for a small numerical change in total planthopper abundance, and therefore would be unlikely to elicit an indirect positive effect on D. scolochloa. Treatments were instituted early in the first generation of 1998 (early May) when late-instar nymphs but few adults were present. For the addition treatments, I obtained planthoppers from nearby pure stands of sprangletop or cordgrass. Host-plant habitat, equal to three times the area occupied by the plant species in the experimental pothole, was swept with a fine-mesh net to capture planthoppers. Planthoppers were quickly transported to the experimental pothole and evenly distributed in the corresponding host-plant habitat. In removal potholes, the entire host-plant habitat was thoroughly swept two times and captured planthoppers only were released outside of the experimental area. All other arthropods were released where they were captured. No planthoppers were added to or removed from the control potholes. However, control potholes and addition potholes (prior to the planthopper addition) were swept with nets to achieve the same level of trampling that the removal plots suffered. All collected insects were quickly returned to their origin.

I surveyed D. scolochloa and $P$. crocea egg densities and parasitism by Anagrus among these 14 potholes for three generations (1998-I, 1998-II, and 1999-I). These egg generations corresponded with the first half of the census period in the previous study. The procedures used to estimate egg densities and parasitism were identical to those described for the census.

A repeated-measures ANOVA was used as an omnibus test for treatment effects on planthopper density or proportion parasitized over the course of the study. Generation was the repeated measure and pothole area was a covariate in the model. A separate analysis was performed for four dependent variables: $D$. scolochloa and P. crocea density (eggs $/ \mathrm{m}^{2}$ ), and proportion of eggs parasitized for species. Areas and densities were $\ln$-transformed and parasitism was arcsine squareroot (proportion) transformed to normalize data distributions and homogenize variances. If there was a significant $(P<0.05)$ treatment or treatment $\times$ generation interaction effect on the dependent variable, separate ANOVAs were performed for each generation. A Tukey's pairwise comparisons test was used to evaluate differences among treatment means within a generation. I controlled for inflated type I error associated with the three nonindependent ANOVAs (one per generation) by using a Bonferroni-corrected level of $\alpha=0.017$ (nominal level of $\alpha$ [0.05]/3 separate tests). This adjusted $\alpha$ was used for both the ANOVA and pairwise contrasts. Data were analyzed using Proc
MIXED in SAS 9.1 (SAS Institute, Cary, North Carolina, USA). This procedure uses maximum likelihood methods to compute $F$ statistics and, therefore, mean and sums of squares were not computed.

For each generation, I determined the Pearson's product moment correlation between densities of $D$. scolochloa and $P$. crocea within potholes $(n=14$ potholes). Because indirect effects of one species on the other may take time to manifest themselves, densities were lagged by zero, one, or two generations. Significances were assessed using a sequential Bonferroni correction (Sokal and Rohlf 1995).

\section{Apparent competition and planthopper persistence}

I experimentally tested whether apparent competition between the two planthopper species can influence the density and likelihood of persistence of one planthopper species in a pothole already occupied by the other planthopper species. In light of the numerical dominance of $D$. scolochloa relative to $P$. crocea within potholes, I focused this study on the persistence of the latter species in areas with and without the former species.

The experiment was conducted during the last year of the planthopper census (1999) and in association with five of the eight large potholes that were included in the census. One hundred small cordgrass patches were created in early May by excavating sods of the grass that completely filled $35 \times 47 \mathrm{~cm}(15 \mathrm{~cm}$ deep $)$ polyethylene bus pans. Pans were used to retain water around cordgrass roots and enable transport of cordgrass patches. Patches of this size are capable of supporting viable populations of $P$. crocea (Cronin and Haynes 2004, Cronin 2007).

Experimental cordgrass patches were sprayed with insecticidal soap to kill developing planthopper nymphs and the pans were placed $>75 \mathrm{~m}$ away from any $P$. crocea sources. Two weeks later, I counted the number of cordgrass ramets per pan. At this time, I also added eight female and four male $P$. crocea (low density) to one half of the pans, and 32 female and 16 male $P$. crocea (high density) to the other half of the pans (density treatment assigned at random). Planthoppers were collected with a sweep net from nearby cordgrass habitat. Thirty minutes after planthopper additions, the patches were inspected and lost planthoppers (dead or dispersed) were immediately replaced. After five days, adult planthoppers were removed. Pans with no planthopper eggs laid were replaced. Because Anagrus is only likely to develop from hosts that are attacked between three and 10 days old (Cronin 2003b, $c$; J. T. Cronin, unpublished data), the experimental host eggs were in an ideal condition for parasitism.

Bus pans with egg-infested cordgrass were transported to one of three sources of Anagrus parasitoids: (1) a sprangletop patch, in which $D$. scolochloa provided the source of parasitoids; (2) a cordgrass patch, in which conspecifics provided the source of parasitoids; and (3) 
none (isolated), in which experimental patches were placed out in isolation from parasitoid sources. The sprangletop and cordgrass patches were relatively large $\left(\geq 80 \mathrm{~m}^{2}\right)$ and known to support populations of planthoppers and parasitoids (see census data). Bus pans were placed at the borders of natural patches and were meant to represent either a newly formed cordgrass patch adjacent to sprangletop, or an extension of an existing cordgrass patch. Bus pans were spaced $\geq 10 \mathrm{~m}$ apart and $\geq 25 \mathrm{~m}$ from natural patches of the other source plant. The isolated treatment involved placing bus pans in the intervening matrix (composed of mixed grasses, primarily smooth brome, [Bromus inermis], foxtail barley [Hordeum jubatum L.], and western wheatgrass [Agropyron smithii]) $\geq 25 \mathrm{~m}$ from natural source populations of Anagrus. Based on mark-recapture studies, $<1 \%$ of $P$. crocea and $A$. columbi disperse $25 \mathrm{~m}$ (Cronin and Haynes 2004, Cronin 2007). Furthermore, I found a fourfold drop off in captures of A. nigriventris colonizing experimental patches of sprangletop placed $3 \mathrm{~m}$ and $25 \mathrm{~m}$ away from a source (J. T. Cronin, unpublished data). There were a total of 15 replicates of each density-source combination, equally spread among the five potholes. $P$. crocea egg densities and parasitism by Anagrus among experimental cordgrass patches were determined for two generations (1999-I and 1999-II) using the procedures described in Planthopper and parasitoid census. Finally, an experimental population was deemed to have persisted if at least one nymph emerged from $P$. crocea eggs in generation 1999-II (based on the presence of successfully cast egg chorions).

I predicted that $P$. crocea density and the likelihood of persistence would be lower, and the proportion of hosts parasitized would be higher, when the experimental population was in close proximity to $D$. scolochloa as compared to when it was in isolation, owing to the presence of D. scolochloa-derived Anagrus parasitoids. The cordgrass-source treatment differed from the other two treatments, not only with regard to the source of Anagrus, but also with the proximity to sources of $P$. crocea immigrants. Therefore, comparisons between the cordgrass-source and other treatments were complicated by the influence of immigrants on population density and persistence. I regard the cordgrass treatment as a seminatural control that provides a baseline measure for the three dependent variables.

Egg densities of $P$. crocea in these small experimental patches were Poisson distributed. To account for this variance structure in modeling the effects of Anagrus source and initial density on the number of eggs laid per square meter, I used Poisson regression (Agresti 1996). Data were analyzed using Proc GLIMMIX in SAS 9.1 with distribution $=$ Poisson. Initial planthopper density and Anagrus source were fixed factors and generation was the repeated measure. The proportion of hosts parasitized per bus pan was analyzed using repeatedmeasures ANOVA. Parasitism data (arcsine square-root transformed) deviated from normality and variances were heterogeneous (based on inspection of residual plots). However, the data were balanced among treatments and therefore robust to these violations of the assumptions of parametric statistics (Shaw and Mitchell-Olds 1993). Treatment effects on P. crocea persistence (a binomial variable) was analyzed using Proc GLIMMIX and distribution = binomial (i.e., a logistic regression).

As in the previous experiment, I treated the above models as omnibus tests for the effect of initial density and Anagrus source on the dependent variables. If there was a significant $(P<0.05)$ source, source $\times$ generation, or source $\times$ density effect, separate tests were performed for each generation. A Tukey's pairwise comparisons test was used to evaluate differences among treatment means within a generation. I controlled for inflated type I error associated with tests performed on two nonindependent generations by using a Bonferroni-corrected level of $\alpha=0.025$ (nominal level of $\alpha$ [0.05]/2 separate tests).

Differences among treatments in the likelihood that the local $P$. crocea population on an experimental patch persisted to the end of the study were analyzed using logistic regression. If the overall test was significant, all possible pairwise tests were performed using the same model but with only two treatments included $(\alpha=0.017$ for each of the three pairwise combinations).

\section{Anagrus host preference/suitability}

A simple laboratory experiment was conducted to determine whether D. scolochloa and P. crocea differed in their preferability or suitability as hosts for Anagrus. During the second generation of 2000, separate pots of insect-free sprangletop and cordgrass (five to six ramets in a $20-\mathrm{cm}$ diameter pot) were caged within clear acetate cylinders $(0.75 \mathrm{~m}$ tall). The base of the cylinder sat flush with the potting soil and the top was covered with fine insect netting. Twenty female and 10 male D. scolochloa and $P$. crocea adults were added to the cages with their respective host plant. Planthoppers were allowed to oviposit for three days and then removed.

After allowing eggs to mature for two days, I placed two pots of each plant species together within a cage constructed of a PVC frame and fine-insect netting. Five female Anagrus were released into each cage and allowed to oviposit in hosts for the remainder of their lives (typically $<2$ d). To assess whether host of origin influenced parasitism, one-half of the trials were conducted with Anagrus derived from D. scolochloa and the other one-half were conducted with Anagrus from $P$. crocea eggs. The rearing procedure for these parasitoids is outlined in Cronin and Strong (1990). The ratio of parasitoids to host eggs was sufficiently low that parasitoid interference, superparasitism, and exhaustion of available hosts would be low. The experiment consisted of a total of 12 replicate cages per Anagrus source. 


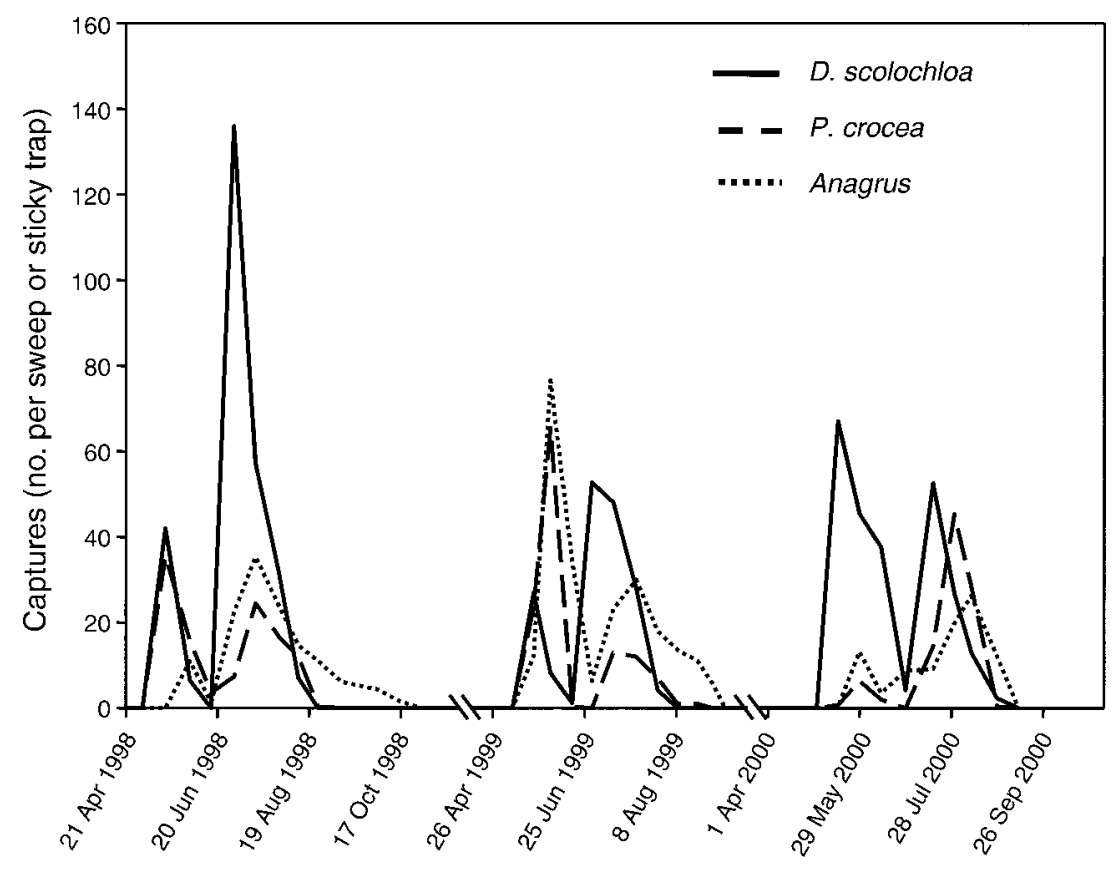

FIG. 1. Captures of adult planthoppers Delphacodes scolochloa and Prokelisia crocea (mean of three sweep sets) and female egg parasitoids Anagrus spp. (mean of four sticky trap captures) from eight prairie potholes in North Dakota, USA, and three years (1998-2000). For clarity, standard errors are not shown.

Ten days after the release of parasitoids, I dissected ramets from each cage and counted the number of healthy and parasitized hosts for each planthopper species. The number of parasitized hosts represents a combination of host preference and ability of the parasitoid offspring to survive for $7-10$ days (early pupal stage). The effect of Anagrus origin on the number of hosts parasitized per planthopper species was analyzed using profile ANOVA (Tabachnick and Fidell 2000). This model accounts for the nonindependence of planthopper species within a cage (because they are being shared among the five parasitoids), and is equivalent to a repeated-measures design. Here, Anagrus source was a fixed factor, planthopper species was the repeated measure and total eggs laid per planthopper species per cage was a covariate in the model. Normality and homogeneity of variances was achieved by $\mathrm{ln}$ transforming host and parasitized host numbers. Data were analyzed using Proc MIXED in SAS.

\section{RESUlts}

\section{Planthopper and parasitoid census}

D. scolochloa and $P$. crocea exhibited two distinct peaks in population density each year (Fig. 1). With the exception of the first generation in 1998, the peak in $P$. crocea density lagged two weeks (one census period) behind the peak in D. scolochloa density. Anagrus trap captures in sprangletop and cordgrass were well correlated in time $(r \geq 0.59, P \leq 0.013$; separate test for each of eight ponds). Based on traps pooled from each host plant habitat, Anagrus also exhibited two distinct generations per year with peaks that either coincided ( $n=4$ generations) or lagged two weeks behind ( $n=2$ generations) P. crocea (Fig. 1).

Cumulative egg densities of $D$. scolochloa averaged $60 \%$ higher than the densities of $P$. crocea $(2766 \pm 761$ vs. $1728 \pm 460 \mathrm{eggs} / \mathrm{m}^{2}$, respectively), but much of this difference was driven by the outbreak of $D$. scolochloa in the 1998-II generation (Fig. 2A). The difference in densities was not significant over the course of six generations $(t=1.19, P=0.29)$. Parasitism of hosts was $21.7 \pm 4.2 \%$ for $D$. scolochloa and $26.6 \pm 5.2 \%$ for $P$. crocea $(t=0.81, P=0.45$; Fig 2B). Interestingly, parasitism of both planthopper eggs reached a maximum one generation following the outbreak of $D$. scolochloa.

\section{Apparent competition experiment}

The addition or removal of nymphal planthoppers significantly influenced densities of D. scolochloa and $P$. crocea eggs over the course of three generations (Fig. 3, Appendix A). In the first generation (just several weeks following treatment applications), D. scolochloa egg density in the Ds+ (D. scolochloa addition) and Ds- (D. scolochloa removal) potholes averaged 5.5 times higher and 3.2 times lower, respectively, than in control potholes (Appendix A; based on Tukey's test, both contrasts $P \leq 0.001$ ). At the same time, $P$. crocea egg density was 5.7 times higher in $\mathrm{Pc}+(P$. crocea addition) than control potholes (Tukey's test, $P<0.001$ ). These treatment effects on density carried through the second generation for $D$. scolochloa (Tukey's tests, $P \leq 0.006$ ), 

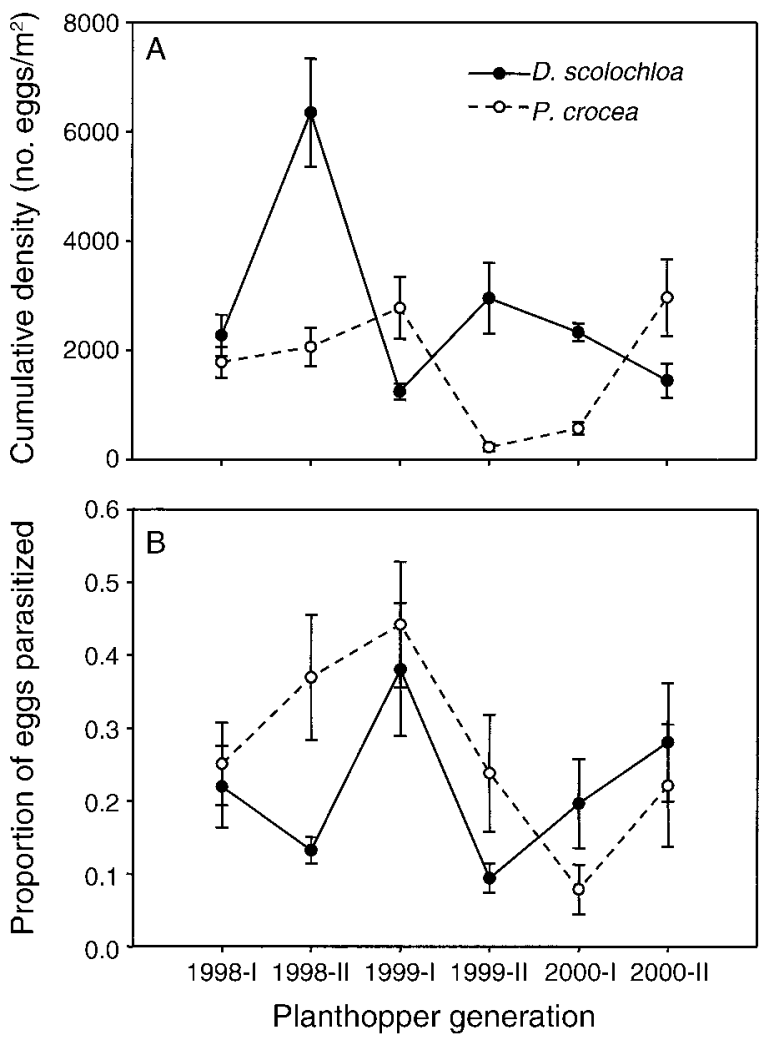

FIG. 2. Census of Delphacodes scolochloa and Prokelisia crocea (A) cumulative egg densities and (B) proportion of eggs parasitized per generation. Values are means \pm SE. Generations are labeled according to year and whether it is the first (I) or second (II) generation of the year.

and only marginally so for $P$. crocea (Tukey's test, $P=$ 0.046).

An almost six-fold increase in $P$. crocea egg densities in the Pc+ potholes had no significant effect on $D$. scolochloa egg densities in the same pothole (Fig. 3A). A repeated-measures ANOVA with only $\mathrm{Pc}+$ and control potholes included revealed no significant treatment or treatment $\times$ generation effect on $D$. scolochloa egg densities (Appendix A). In contrast, the fivefold increase in D. scolochloa egg densities in the Ds+ potholes had a dramatic negative effect on $P$. crocea egg densities (Fig. 3B; Appendix A, Ds+ vs. control, $P=0.016$ ). The density of $P$. crocea in Ds+ potholes declined significantly over time (Appendix A, $P=0.001$ ), and by the end of the study was 5.1 times lower than the density in control potholes. Interestingly, the threefold reduction of $D$. scolochloa in potholes had no impact on $P$. crocea egg densities over time (Ds- vs. control, $P=0.740$ ).

There was no significant correlation between $D$. scolochloa and $P$. crocea egg densities within potholes for any of the three generations (Appendix B). However, $D$. scolochloa density at generation $t$ was significantly negatively correlated with $P$. crocea densities at $t+1$ and $t+2$. The inverse was not true: $P$. crocea density was uncorrelated with $D$. scolochloa density lagged one or two generations into the future.

For D. scolochloa, the planthopper density addition/ removal treatments had no significant effect on the proportion of eggs parasitized by Anagrus (Appendix A, Fig. 4A). However, the proportion parasitized did increase significantly over time $(P=0.027)$, averaging $0.28 \pm 0.04$ in generation 1999-I. By comparison, parasitism of $P$. crocea eggs was strongly influenced by experimental manipulation of planthopper densities (Appendix A, Fig. 4B). Starting in the first generation, parasitism of $P$. crocea eggs already was 1.6 times higher in the Ds+ relative to control potholes (Tukey's test, $P=$ 0.031; a marginally significant result based on accepted level of $\alpha$ ). Across all three generations, this difference was highly significant (Appendix A; $P=0.005$ ). On average, parasitism of $P$. crocea in Ds+ potholes was 2.04 \pm 0.23 times greater than in control potholes (based on generation means). There was no difference in parasitism of $P$. crocea between Ds- and control potholes $(P=$ 0.347) or parasitism of D. scolochloa between Ps+ and Control potholes $(P=0.90$; Appendix A).

\section{Apparent competition and planthopper persistence}

Within small experimental cordgrass patches, $P$. crocea egg density and the likelihood that a local
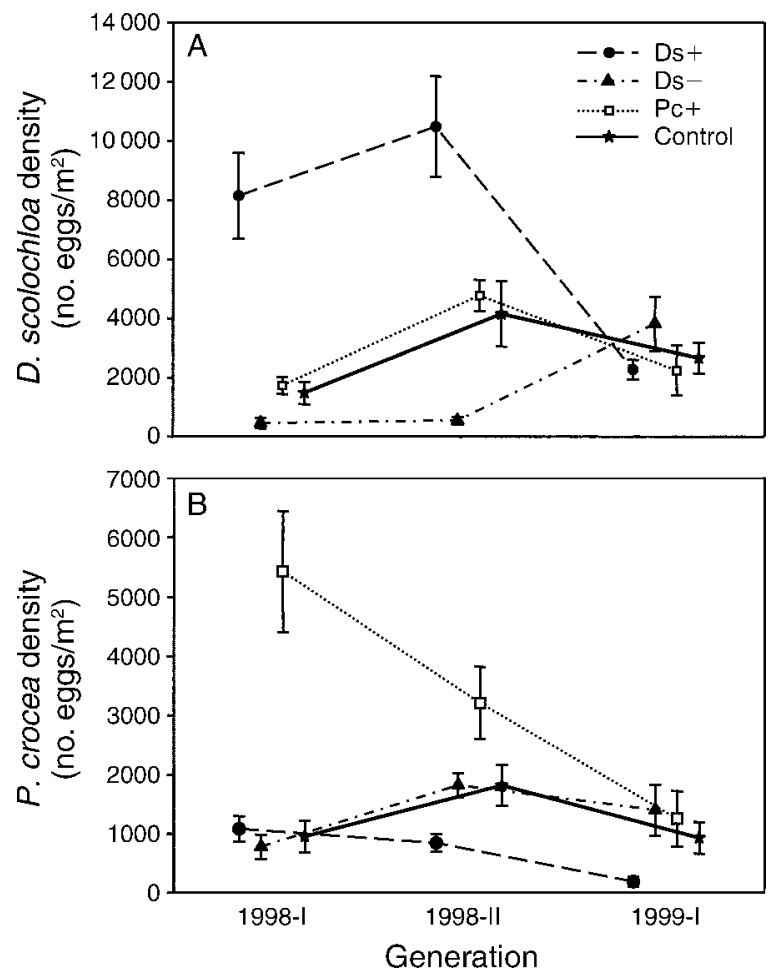

FIG. 3. Density (mean \pm SE) of (A) Delphacodes scolochloa and (B) Prokelisia crocea subjected to different nymphal addition and removal treatments: Ds + is the addition of $D$. scolochloa, Ds- is the removal of D. scolochloa, and Ps+ is the addition of $P$. crocea to individual prairie potholes. Control potholes are unmanipulated. 

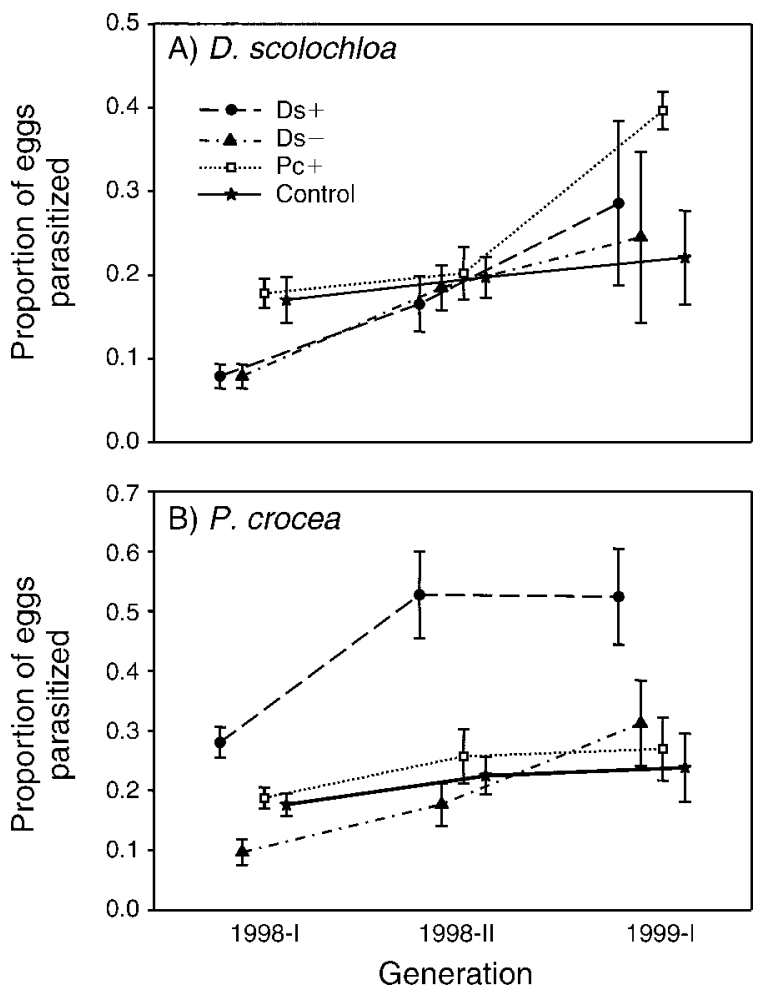

FIG. 4. Proportion (mean \pm SE) of eggs of (A) Delphacodes scolochloa and (B) Prokelisia crocea parasitized by Anagrus spp. See Fig. 3 for the definitions of treatments.

population persisted through two generations was strongly influenced by Anagrus source and initial density treatments (Appendix C, Figs. 5A and 6). Planthopper egg densities at the start of the study (1999-I) were strongly influenced by initial density of adult planthoppers $\left(F_{1,84}=186.5, P<0.001\right)$ but were unaffected by Anagrus source $\left(F_{2,84}=1.25, P=0.242\right)$. These results verify that there was no bias in egg densities among Anagrus source populations at the start of the study, and that the density treatment was successful. In fact, the addition of 32 adult planthoppers resulted in an egg density that was 4.2 times higher on average than the density in the eight-adult bus pans. Differences between the low and high initial-density treatment persisted through the second generation of the study (i.e., no significant density $\times$ generation interaction term in Appendix C). In contrast, there was a significant source $\times$ generation interaction (Appendix $C$ ) that resulted in significant differences among all three Anagrus sources in 1999-II $\left(F_{2,84}=45.49, P<0.001\right.$; all pairwise comparisons, $P<0.001)$. Most notably, $P$. crocea egg densities had the following rank with respect to Anagrus source: cordgrass $>$ isolated $>$ sprangletop (Fig. 5A). Only $53 \%$ of the local $P$. crocea populations adjacent to sprangletop persisted for the duration of the study (Fig. 6). The likelihood that $P$. crocea persisted in the sprangletop-associated populations (initial density treatments combined) was significantly lower than in either the isolated or cordgrass-associated populations (logistic regression; $\chi^{2}=6.43, P=0.011$ and $\chi^{2}=17.26, P<$ 0.001 , respectively).

Parasitism by Anagrus was a significant factor explaining the differences in P. crocea egg density and likelihood of persistence among Anagrus sources (Appendix C). The proportion parasitized was highest for patches adjacent to sprangletop, intermediate for patches adjacent to cordgrass and lowest for isolated patches (comparison of least-squares means, $P \leq 0.006$ for all pairwise comparisons; Fig. 5B). On average, $P$. crocea in sprangletop-associated cordgrass patches suffered parasitism rates that were four times and two times higher than the rates for isolated and cordgrassassociated patches, respectively. Finally, the proportion of $P$. crocea eggs parasitized was inversely related to initial density (Fig. 5B).

\section{Anagrus host preference/suitability}

Among cages containing equal-aged hosts of both planthopper species, I could find no evidence that Anagrus preferred or survived better on one species over the other $\left(F_{1,22}=2.57, P=0.123\right.$; Fig. 7$)$. Also, the source of Anagrus did not significantly affect the
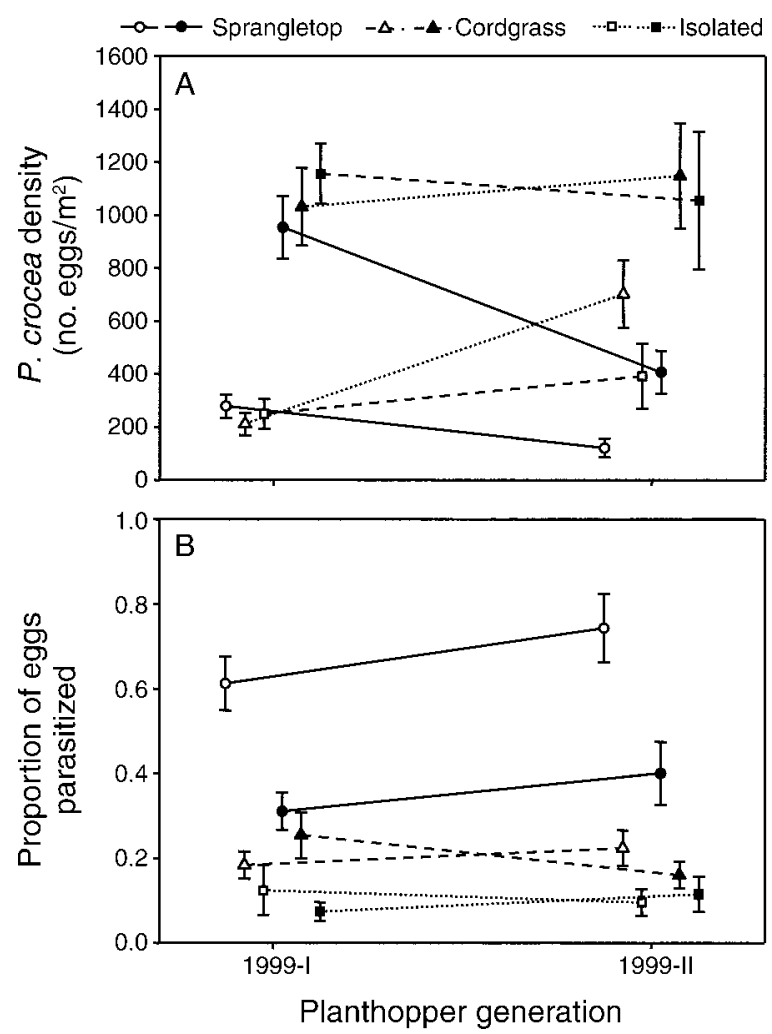

FIG. 5. The effects of Anagrus source (sprangletop, cordgrass, or isolated) and initial planthopper density on (A) Prokelisia crocea egg density and (B) mean proportion of $P$. crocea eggs parasitized in experimental bus pans of cordgrass. Values are means \pm SE. Open and solid symbols represent the low and high planthopper initial-density treatments, respectively. 


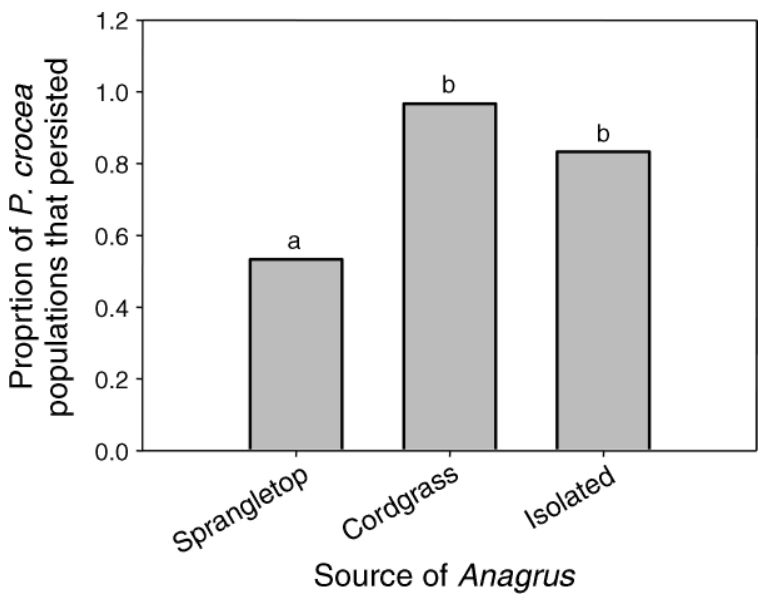

FIG. 6. Proportion of experimental Prokelisia crocea populations that persisted for two generations with respect to the type of adjacent Anagrus source population. Based on logistic regression, source had a significant effect on establishment $\left(\chi^{2}=18.09, P=0.001\right)$. Treatment levels with different letters were significantly different $(P \leq 0.011)$.

preference/suitability of host species $\left(F_{1,22}=0.06, P=\right.$ $0.813)$. Finally, even though there was an average of $32 \%$ more $D$. scolochloa than $P$. crocea eggs per cage $\left(F_{1,23}=7.75, P=0.011\right)$, egg number per species had no effect on number parasitized $\left(F_{1,22}=2.34, P=0.140\right)$.

\section{Discussion}

Host-parasitoid systems have been invaluable to the development and testing of apparent competition theory (e.g., Settle and Wilson 1990, Bonsall and Hassell 1997, 1998, 1999, 2000, Morris et al. 2004). In that regard, this study represents one of the few field experiments to examine apparent competition in the context of a fragmented habitat or metacommunity (but see van Nouhuys and Hanski 2000). Despite utilizing different plant species along the margins of patchily distributed prairie potholes, D. scolochloa and $P$. crocea appear to interact indirectly through shared parasitoids $(A$. columbi and $A$. nigriventris). When $D$. scolochloa densities were experimentally elevated, $P$. crocea densities declined over the next two generations. This result would explain the negative correlations between $D$. scolochloa densities at $t$ and the densities of $P$. crocea at $t+1$ and $t+2$. As expected if indirect negative interactions were mediated by natural enemies, parasitism of $P$. crocea eggs increased more than twofold following the increase in $D$. scolochloa density. That this increase was becoming evident in the first generation of the study suggests there was a short-term aggregative response by Anagrus to the elevated densities in the Ds+ potholes (e.g., owing to an increase in oviposition rate, patch time, area-restricted search, immigration as the combined density of both species increases; see also Waage 1983, Casas 1989, Wiskerke and Vet 1994, Umbanhowar et al. 2003). Apparent competition is expected to involve both short-term and long-term (numerical) responses by the shared natural enemies (Holt 1977, Holt and Kotler 1987, Bonsall and Hassell 1999).

Interestingly, the experimental reduction of $D$. scolochloa density had no impact on $P$. crocea density or parasitism. These data might suggest that apparent competition is only evident when densities of $D$. scolochloa are relatively high, such as during outbreak periods (e.g., 1998-II; Fig. 1). This is analogous to the common situation for resource competition in which negative interactions are most evident at high density (Strong 1985). I note here that the range of D. scolochloa densities established in the experiment were comparable to those found in undisturbed potholes over the course of six generations (cf. Fig. 2A and Fig. 3A).

Experimentally elevated densities of $P$. crocea had no effect on $D$. scolochloa density or parasitism in the same potholes, suggesting that the former species is an inferior apparent competitor to the latter species. This finding is consistent with the published literature on both resource and apparent competition that pairwise interactions are commonly asymmetric (Connell 1983, Brassil and Abrams 2004, Hambäck et al. 2006). The superiority of $D$. scolochloa over $P$. crocea likely can be attributed to any combination of the following three factors: the larger source population size of $D$. scolochloa, the larger spatial scale of the experimental manipulation of $D$. scolochloa, and/or the presence of a phenological refuge from parasitism for D. scolochloa. Among the experimental potholes, sprangletop covered 3.2 times more area than cordgrass (see Methods). Based on data from the control potholes, the estimated total number of $D$. scolochloa at a single pothole was $10.3 \pm 1.7$ (range, $3.2-$ $24.4 ; n=12$ potholes) times greater than the number of $P$. crocea during the course of the study ([D. scolochloa density $\times$ (area of sprangletop/area of cordgrass)]/P. crocea density). Therefore, $P$. crocea may have been too rare (in a relative sense) to provide a large enough source

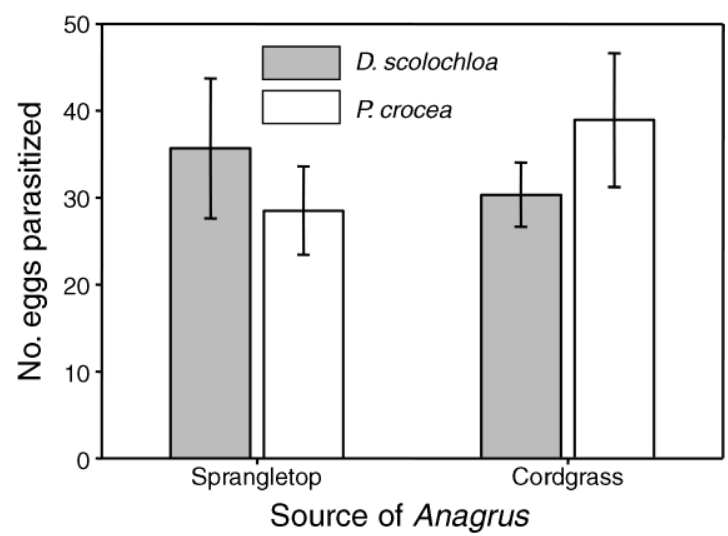

FIG. 7. Number of Delphacodes scolochloa and Prokelisia crocea eggs (mean \pm SE) parasitized by Anagrus within the same cage. Anagrus was derived from either D. scolochloa eggs on sprangletop or $P$. crocea eggs on cordgrass. 


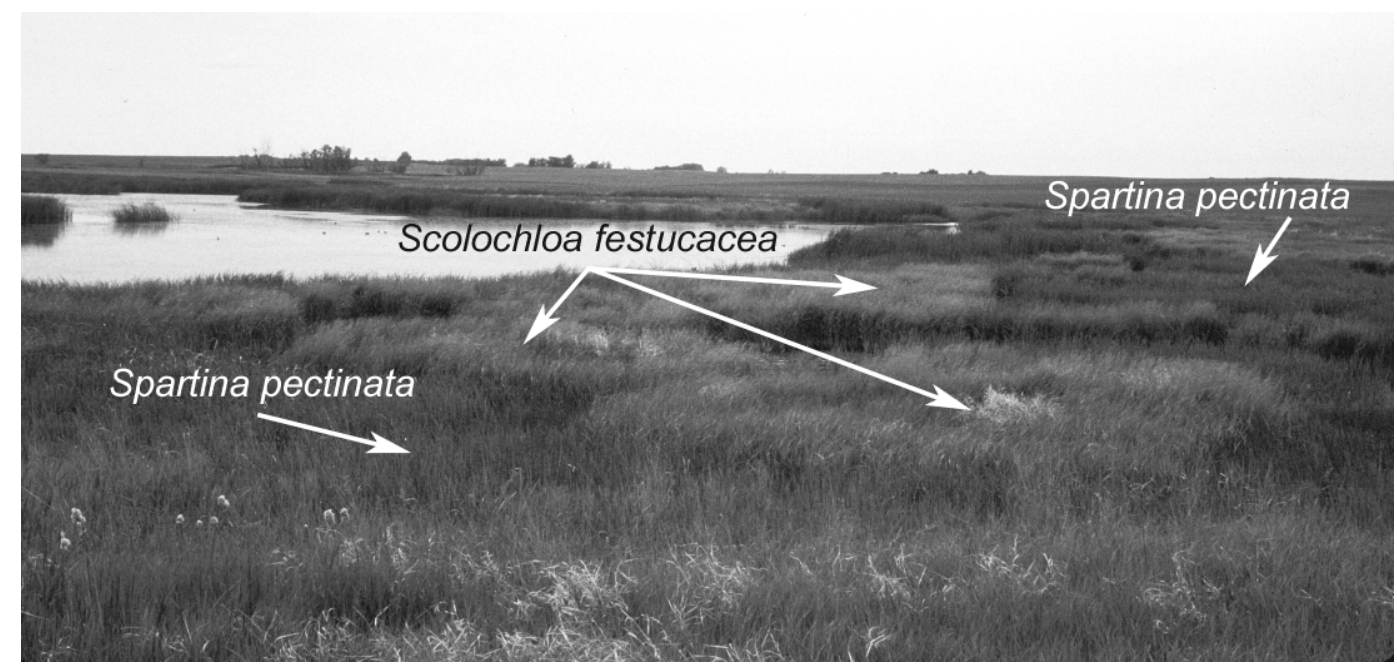

Plate 1. Prairie pothole (Site 109) in Nelson County, North Dakota (USA), with patches of Sprangletop (Scolochloa festucacea) and prairie cordgrass (Spartina pectinata). Photo credit: J. T. Cronin.

of Anagrus parasitoids to have a statistically significant negative effect on $D$. scolochloa (through an aggregative or numerical response [Chaneton and Bonsall 2000, van Veen et al. 2006]). Even an experimental sixfold increase in $P$. crocea (as in the Pc+ treatment) would have left $D$. scolochloa an average of 1.7 times more abundant. Also, there was no evidence of positive frequency-dependent parasitism of hosts by Anagrus (see Holt 1984, Abrams and Matsuda 1996, Abrams 1999a). Despite being rare, parasitism in my experiments was always higher for $P$. crocea than D. scolochloa.

A second possible factor contributing to the superiority of D. scolochloa is that Anagrus may have responded aggregatively or numerically only to largescale changes in host abundance. Within experimental potholes, density manipulations of $P$. crocea spanned an area 3.2 times smaller than the area over which $D$. scolochloa was manipulated (owing to differences in the area of coverage of the two host plants). The smallerscale change in $P$. crocea density may have been insufficient to increase recruitment, retention or foraging efficiency of Anagrus in potholes that would translate into elevated parasitism rates of one or both host species. At present, I have no data on whether Anagrus exhibits a scale-dependent response to changes in host density. However, a number of studies have demonstrated that scale is important in determining the relationship between host density and proportion parasitized (e.g., Heads and Lawton 1983, Rothman and Darling 1991, Lill 1998).

The final factor likely contributing to the superiority of $D$. scolochloa is the presence of a better phenological match between adult Anagrus and P. crocea hosts than Anagrus and D. scolochloa hosts. The peak in abundance of $D$. scolochloa eggs preceded the peak for $P$. crocea eggs by two weeks in five of six generations. Anagrus densities were based on cumulative captures on sticky traps over a two-week period of time. If we use the midpoint of this period as the date for the Anagrus census, then the peak in parasitoid abundance most commonly occurred one week after the peak for $P$. crocea (four of six generations) and three weeks after the peak for D. scolochloa (five of six generations). Because host eggs of both species are most suitable for parasitoid attack between three and 10 days post oviposition (Cronin 2003b, Cronin and Wilson 2007), a higher proportion of the $P$. crocea population would have been in a suitable stage for attack when Anagrus was at its peak. In contrast, many of the D. scolochloa eggs laid early in the season would have been too old to be successfully parasitized by Anagrus emerging during its peak period. Russell and Louda (2005) found a similar phenological mismatch between two thistle species and a shared flowerhead weevil, Rhinocyllus conicus. At this point in time, I do not know the underlying cause for the phenological mismatch between D. scolochloa and Anagrus. One possible explanation is that D. scolochloa is a relatively novel or geographically restricted host species for $A$. nigriventris and $A$. columbi, and the regional population of parasitoids has not yet adapted to the phenology of this host. Unfortunately, there is no information on the range of overlap for this hostparasitoid interaction (beyond the study area) that would allow for an evaluation of this hypothesis (see Cronin and Wilson 2007).

The asymmetric indirect interaction between the $D$. scolochloa and P. crocea did not appear to be due to differences in Anagrus' ability to successfully parasitize the two species. When presented with a choice between similar-aged eggs of both planthopper species, Anagrus parasitized equivalent numbers of each. Also, the number parasitized per planthopper species did not depend on the host of origin of Anagrus. In this experiment, a difference in the number of parasitized 
hosts could have been an indication of a strong preference for that species and/or that species was more suitable for larval parasitoid development. Therefore, I could not rule out the possibility that one host was preferred for oviposition but the other host was more suitable for larval development. Regardless, these data suggest that when $D$. scolochloa and $P$. crocea eggs overlap phenologically, they are expected to produce equivalent numbers of parasitoid offspring.

Whereas most field studies of apparent competition have only documented interaction effects on the relative fitnesses or abundances of focal species (e.g., Rand 2003, Lau and Strauss 2005, Hambäck et al. 2006), this is one of only a few studies (see also Zwölfer 1979, Müller and Godfray 1999, van Nouhuys and Hanski 2000) to confirm the theoretical expectation that interactions mediated by a shared natural enemy can cause the local extinction of one prey species (Nicholson and Bailey 1935, Holt 1977, Holt and Lawton 1994). In an experiment in which small populations of $P$. crocea (on $0.16-\mathrm{m}^{2}$ cordgrass patches) were established either in close proximity to D. scolochloa or in isolation, I found that after two generations not only were densities more than 2.5 times lower, but also the likelihood of extinction was $36 \%$ higher in the former than the latter populations. The very high rates of parasitism in the populations associated with $D$. scolochloa (a mean of $74 \%$ in the low-density treatment) likely contributed to the high frequency of extinction; in fact, for three replicates, parasitism was the sole cause for extinction (i.e., $100 \%$ parasitism). High parasitism also may have reduced local population densities to levels at which demographic stochasticity or Allee effects became dominant forces in the population (e.g., Lande 1987, Dennis 2002, Bascompte 2003, Engen et al. 2003, Drake 2006).

Based on an examination of 43 potholes in northeastern North Dakota, small cordgrass patches of the size used in the above experiment were common (J. T. Cronin, unpublished data). For five potholes, only one to three small patches comprised the total amount of cordgrass habitat present at a pothole. These cordgrass patches are known to be capable of supporting viable, persistent populations of $P$. crocea (Cronin and Haynes 2004, Cronin 2007). However, D. scolochloa, which typically is found in much larger sprangletop patches, may cause the extinction or inhibit the establishment of $P$. crocea in adjacent small cordgrass patches through apparent competition. If these small cordgrass patches represent important stepping stones for $P$. crocea movement among potholes, apparent competition may also limit the spatial spread of this species or reduce connectivity among larger $P$. crocea populations (Baum et al. 2004).

In larger, natural patches of cordgrass, i.e., those used in the apparent competition experiment that averaged 10 $\mathrm{m}^{2}$, I did not observe any local extinctions of $P$. crocea. However, in response to elevated densities of $D$. scolochloa, densities of $P$. crocea declined over three generations by more than fivefold relative to densities in control potholes. Given sufficient time, these populations may have continued to decline to extinction, as theory would predict (Nicholson and Bailey 1935, Holt 1977, Holt and Lawton 1994). This study suggests that in potholes with small cordgrass patches $\left(\leq 0.25 \mathrm{~m}^{2}\right)$, and possibly in potholes with cordgrass patches one to two orders of magnitude larger, D. scolochloa may limit membership of $P$. crocea in local subcommunities of a larger metacommunity.

For two species that share a limiting resource, coexistence is possible if the dominant resource competitor suffers more from apparent competition (Holt et al. 1994, Leibold 1996, Grover and Holt 1998, Abrams $1999 b$ ). In my study system, D. scolochloa and $P$. crocea utilize different host plants and therefore do not compete for limiting resources. However, they do interact indirectly through a shared parasitoid. If apparent competition can cause the local extinction of $P$. crocea, how is coexistence possible between the two planthopper species in this prairie pothole landscape? A number of recent spatially explicit theoretical models provide insight into the possible mechanisms promoting coexistence at the metacommunity level (Comins and Hassell 1996, Holt 1997, Bonsall and Hassell 2000, King and Hastings 2003, Holt and Hoopes 2004). In theory, D. scolochloa and P. crocea could coexist if there is little movement by Anagrus between the two host-plant habitats (Hanski 1981, Holt 1997, Holt and Hoopes 2004). However, this is not likely the case. A. nigriventris has a broad range of hosts and host plants (Chiappini et al. 1996), and both Anagrus species commonly cross patch boundaries between sprangletop, cordgrass and a variety of other plant species (Cronin 2003c; J. T. Cronin, unpublished data).

A more likely mechanism of coexistence between $D$. scolochloa and $P$. crocea is a trade-off between dispersal and fecundity (Comins and Hassell 1996, Bonsall and Hassell 2000, King and Hastings 2003). The inferior apparent competitor persists at the metacommunity level through temporary escape in space from the indirect interactions (mediated through natural enemies) with the superior (and more fecund) apparent competitor. This is analogous to the fugitive coexistence of an inferior resource competitor in subdivided habitats (e.g., Levins and Culver 1971, Hastings 1980, Hanski 1983, Nee and May 1992). In my study system, female $D$. scolochloa are predominantly brachypterous with limited capability for flight (Cronin and Wilson 2007) whereas female $P$. crocea are predominantly macropterous (Cronin 2003a). The laboratory experiment on Anagrus host preference/suitability also revealed that D. scolochloa lays $32 \%$ more eggs than $P$. crocea over a three day period. Among wing-dimorphic species, a trade-off between reproduction and dispersal is common (Roff 1984, 1986, Zera 1984, Denno et al. 1989, Cronin and Wilson 2007). Therefore, it is conceivable that $P$. 
crocea persists in the Pothole region of North Dakota because of its fugitive lifestyle.

\section{Metacommunity implications}

For almost 40 years, metapopulation theory has provided a foundation for studying subdivided populations (reviewed in Hanski 1999). It is based on the assumption that dispersal and extinction are the dominant forces affecting the spatial distribution of a single species. Metacommunity theory is a logical and recent extension of metapopulation theory. It accepts that species do not live in isolation and that interactions among species may be important in determining local and regional community structure (Holyoak et al. 2005). In real multispecies systems, indirect interactions mediated through shared natural enemies (i.e., apparent competition) are likely to be common (Holt and Lawton 1993, 1994, Chaneton and Bonsall 2000). Shared natural enemies can either limit or promote membership at the local and regional level depending on prey and predator dispersal rates and predator habitat or prey selection behavior (Holt 1977, Comins and Hassell 1996, Bonsall and Hassell 2000, Shurin and Allen 2001, King and Hastings 2003). For example, in the presence of a shared predator, an inferior apparent competitor may exhibit a higher local extinction rate (as was found for $P$. crocea) and therefore a lower patch occupancy rate than when the shared predator is absent. If there is a trade-off between fecundity and dispersal among apparent competitors, the inferior species may also be limited to occupying more isolated patches in the metacommunity (Comins and Hassell 1996, Bonsall and Hassell 2000, King and Hastings 2003).

There are four conceptual models used to explain metacommunity structure: the patch-dynamic, speciessorting, mass effects, and neutral models (Holyoak et al. 2005). The type of species interaction that is emphasized in these models, with the exception of the neutral model, is interspecific competition, and many empirical studies reflect this interaction bias. The most common approach is to study species within the same trophic level, often within the same assemblage or guild. Based on a literature search in Web of Science using the key word "metacommunity" and the years 1990-2007 (as of 31 January 2007), I found that $80 \%$ of 31 field-based studies were restricted to one trophic level (Web of Science available online). ${ }^{2}$ However, apparent competition readily fits within the rubric of the above metacommunity models. Without the inclusion of natural enemies in metacommunity surveys, erroneous conclusions may be drawn regarding the underlying mechanisms determining metacommunity structure.

Overall, this field study provides clear evidence that apparent competition can lead to the local extinction of a species in a fragmented habitat. From a metacommunity perspective, this indirect interaction can limit

${ }^{2}\langle$ http://scientific.thomson.com/products/wos/ $\rangle$ membership in a local community and significantly affect the pattern of occupancy across the landscape. Bias against studying multiple trophic levels limits our understanding of the role that natural enemies play in determining metacommunity structure. An important avenue of future research would be to examine the relative importance of bottom-up, top-down, and lateral (e.g., interference competition) forces on metacommunity structure. Moreover, given the sensitivity of higher trophic levels to habitat fragmentation (e.g., Pimm and Lawton 1977, Pimm 1991, Holt 1996), it would be valuable to explore how the loss or increased fragmentation of habitats affects the strength of apparent competition and other top-down forces (e.g., predation by specialists, trait-mediated predator effects).

\section{ACKNOWLEDGMENTS}

The following people assisted with the field work: R. Beasler, J. Geber, T. Hanel, S. Jorde, M. Szymanski, A. Widdell, and M. Williams. K. Thompson (U.S. Fisheries and Wildlife Service; Sites 100 and 109) and D. and J. Ralston (N29 sites) graciously allowed me to conduct my research on their properties (N29 sites). Special thanks to S. V. Triapitsyn for identifying and providing mounted specimens of my Anagrus species, and S. W. Wilson for taxonomic work on D. scolochloa. K. Haynes and two anonymous reviewers provided helpful comments on an earlier draft of this manuscript. This work was supported by the University of North Dakota, ND EPSCoR (EPS-9874802), the UND Alumni Foundation, Louisiana State University, and National Science Foundation grants DEB-9973789, DEB0211359, and DEB-0515764.

\section{Literature Cited}

Abrams, P. A. 1999a. The adaptive dynamics of consumer choice. American Naturalist 153:83-97.

Abrams, P. A. 1999b. Is predator-mediated coexistence possible in unstable systems? Ecology 80:608-621.

Abrams, P. A., and H. Matsuda. 1996. Positive indirect effects between prey species that share predators. Ecology 77:610 616.

Agresti, A. 1996. An introduction to categorical data analysis. Wiley, New York, New York, USA.

Bascompte, J. 2003. Extinction thresholds: insights from simple models. Annales Zoologici Fennici 40:99-114.

Baum, K. A., K. J. Haynes, F. P. Dillemuth, and J. T. Cronin. 2004. The matrix enhances the effectiveness of corridors and stepping stones. Ecology 85:2671-2676.

Bonsall, M. B., J. C. Bull, N. J. Pickup, and M. P. Hassell. 2005. Indirect effects and spatial scaling affect the persistence of multispecies metapopulations. Proceeding of the Royal Society B 272:1465-1471.

Bonsall, M. B., and M. P. Hassell. 1997. Apparent competition structures ecological assemblages. Nature 388:371-378.

Bonsall, M. B., and M. P. Hassell. 1998. Population dynamics of apparent competition in a host-parasitoid assemblage. Journal of Animal Ecology 67:918-929.

Bonsall, M. B., and M. P. Hassell. 1999. Parasitoid-mediated effects: apparent competition and the persistence of hostparasitoid assemblages. Researches on Population Ecology 41:59-68.

Bonsall, M. B., and M. P. Hassell. 2000. The effects of metapopulation structure on indirect interactions in hostparasitoid assemblages. Proceedings of the Royal Society of London B 267:2207-2212.

Brassil, C. E., and P. A. Abrams. 2004. The prevalence of asymmetrical indirect effects in two-host-one-parasitoid systems. Theoretical Population Biology 66:71-82. 
Casas, J. 1989. Foraging behaviour of a leafminer parasitoid in the field. Ecological Entomology 14:257-265.

Chaneton, E. J., and M. B. Bonsall. 2000. Enemy-mediated apparent competition: empirical patterns and the evidence. Oikos 88:380-394.

Chiappini, E., S. V. Triapitsyn, and A. Donev. 1996. Key to the Holarctic species of Anagrus Haliday (Hymenoptera: Mymaridae) with a review of the Nearctic and Palaearctic (other than European) species and descriptions of new taxa. Journal of Natural History 30:551-595.

Comins, H. N., and H. P. Hassell. 1996. Persistence of multispecies host-parasitoid interactions in spatially distributed models with local dispersal. Theoretical Population Biology 183:19-28.

Connell, J. H. 1983. On the prevalence and relative importance of interspecific competition: evidence from field experiments. American Naturalist 122:661-696.

Cronin, J. T. 2003a. Movement and spatial population structure of a prairie planthopper. Ecology 84:1179-1188.

Cronin, J. T. 2003b. Patch structure, oviposition behavior, and the distribution of parasitism risk. Ecological Monographs 73:283-300.

Cronin, J. T. 2003c. Matrix heterogeneity and host-parasitoid interactions in space. Ecology 84:1506-1516.

Cronin, J. T. 2007. From population sources to sieves: the matrix alters host-parasitoid source-sink structure. Ecology 88:2966-2976.

Cronin, J. T., and K. J. Haynes. 2004. An invasive plant promotes unstable host-parasitoid patch dynamics. Ecology 85:2772-2782.

Cronin, J. T., and D. R. Strong. 1990. Biology of Anagrus delicatus (Hymenoptera: Mymatidae), an egg parasitoid of Prokelisia marginata (Homoptera: Delphacidae). Annals of the Entomological Society of America 83:846-854.

Cronin, J. T., and S. W. Wilson. 2007. Description, life history, and parasitism of a new species of delphacid planthopper (Hemiptera: Fulgoroidea). Annals of the Entomological Society of America 100:640-648.

Dennis, B. 2002. Allee effects in stochastic populations. Oikos 96:389-401.

Denno, R. F., K. L. Olmstead, and E. S. McCloud. 1989. Reproductive cost of flight capability: a comparison of life history traits in wing dimorphic planthoppers. Ecological Entomology 14:31-44.

Drake, J. M. 2006. Extinction times in experimental populations. Ecology 87:2215-2220.

Engen, S., R. Lande, and B. E. Sæther. 2003. Demographic stochasticity and Allee effects in populations with two sexes. Ecology 84:2378-2386.

Gould, F. W. 1968. Grass systematics. McGraw-Hill, New York, New York, USA.

Grover, J. P., and R. D. Holt. 1998. Disentangling resource and apparent competition: realistic models for plant-herbivore communities. Journal of Theoretical Biology 191:353-376.

Hambäck, P. A., J. A. Stenberg, and L. Ericson. 2006. Asymmetric indirect interactions mediated by a shared parasitoid: connecting species traits and local distribution patterns for two chrysomelid beetles. Oecologia 148:475-481.

Hanski, I. 1981. Coexistence of competitors in patchy environment with and without predation. Oikos 37:306-312.

Hanski, I. 1983. Coexistence of competitors in patchy environment. Ecology 64:493-500.

Hanski, I. 1999. Metapopulation ecology. Oxford University Press, New York, New York, USA.

Hastings, A. 1980. Disturbance, coexistence, history, and competition for space. Theoretical Population Biology 18: 363-373.

Heads, P. A., and J. H. Lawton. 1983. Studies on the natural enemy complex of the holly leafminer: the effect of scale on the detection of aggregative responses and the implications for biological control. Oikos 40:267-276.
Hitchcock, A. S. 1963. Manual of the grasses of the United States. Dover Publications, New York, New York, USA.

Holder, M. W., and S. W. Wilson. 1992. Life history and descriptions of the immature stages of the planthopper Prokelisia crocea (Van Duzee) (Homoptera Delphacidae). Journal of the New York Entomological Society 100:491-497.

Holt, R. D. 1977. Predation, apparent competition and the structure of prey communities. Theoretical Population Biology 12:197-229.

Holt, R. D. 1984. Spatial heterogeneity, indirect interactions, and the coexistence of prey species. American Naturalist 124: 377-406.

Holt, R. D. 1996. Food webs in space: an island biogeographic perspective. Pages 313-323 in G. A. Polis and K. O. Winemiller, editors. Food webs: integration of patterns and dynamics. Chapman and Hall, New York, New York, USA.

Holt, R. D. 1997. From metapopulation dynamics to community structure: some consequences of spatial heterogeneity. Pages 149-164 in I. Hanski and M. E. Gilpin, editors. Metapopulation biology. Academic Press, New York, New York, USA.

Holt, R. D., J. Grover, and D. Tilman. 1994. Simple rules for interspecific dominance in systems with exploitative and apparent competition. American Naturalist 144:741-771.

Holt, R. D., and M. F. Hoopes. 2004. Food web dynamics in a metacommunity context. Pages 68-93 in M. Holyoak, M. A. Leibold, and R. D. Holt, editors. Metacommunities: spatial dynamics and ecological communities. University of Chicago Press, Chicago, Illinois, USA.

Holt, R. D., and B. P. Kotler. 1987. Short-term apparent competition. American Naturalist 130:412-430.

Holt, R. D., and J. H. Lawton. 1993. Apparent competition and enemy-free space in insect host-parasitoid communities. American Naturalist 142:623-645.

Holt, R. D., and J. H. Lawton. 1994. The ecological consequences of shared natural enemies. Annual Review of Ecology and Systematics 25:495-520.

Holyoak, M., M. A. Leibold, N. Mouquet, R. D. Holt, and M. F. Hoopes. 2005. Metacommunities: a framework for largescale community ecology. Pages 1-31 in M. Holyoak, M. A. Leibold, and R. D. Holt, editors. Metacommunities: spatial dynamics and ecological communities. University of Chicago Press, Chicago, Illinois, USA.

Horn, H. S., and R. H. MacArthur. 1972. Competition among fugitive species in a harlequin environment. Ecology 53:749752.

King, A. A., and A. Hastings. 2003. Spatial mechanisms for coexistence of species sharing a common natural enemy. Theoretical Population Biology 64:431-438.

Lande, R. 1987. Extinction thresholds in demographic models of territorial populations. American Naturalist 130:624-635.

Lau, J. A., and S. Y. Strauss. 2005. Insect herbivores drive important indirect effects of exotic plants on native communities. Ecology 86:2990-2997.

Leibold, M. A. 1996. A graphical model of keystone predators in food webs: trophic regulation of abundance, incidence, and diversity patterns in communities. American Naturalist 147:784-812.

Levins, R., and D. Culver. 1971. Regional coexistence of species and competition between rare species. Proceedings of the National Academy of Sciences (USA) 68:1246-1248.

Lill, J. T. 1998. Density dependent parasitism of the hackberry nipplegall maker (Homoptera: Psyllidae): a multi-scale analysis. Environmental Entomology 27:657-661.

Morris, R. J., O. T. Lewis, and H. C. J. Godfray. 2004. Experimental evidence for apparent competition in a tropical forest food web. Nature 428:310-313.

Morris, R. J., O. T. Lewis, and H. C. J. Godfray. 2005. Apparent competition and insect community structure: towards a spatial perspective. Annales Zoologici Fennici 42:449-462. 
Müller, C. B., and H. C. J. Godfray. 1999. Predators and mutualists influence the exclusion of aphid species from natural communities. Oecologia 119:120-125.

Nee, S., and R. M. May. 1992. Dynamics of metapopulations: habitat destruction and competitive coexistence. Journal of Animal Ecology 61:37-40.

Nicholson, A. J., and V. A. Bailey. 1935. The balance of animal populations. Part I. Proceedings of the Zoological Society of London 3:551-598.

Pimm, S. L. 1991. The balance of nature. University of Chicago Press, Chicago, Illinois, USA.

Pimm, S. L., and J. H. Lawton. 1977. Number of trophic levels in ecological communities. Nature 268:329-331.

Rand, T. A. 2003. Herbivore-mediated apparent competition between two salt marsh forbs. Ecology 84:1517-1526.

Roff, D. A. 1984. The cost of being able to fly: a study of wing polymorphism in two species of crickets. Oecologia 63:30-37.

Roff, D. A. 1986. The evolution of wing dimorphism in insects. Evolution 40:1009-1020.

Rothman, L. D., and D. C. Darling. 1991. Spatial density dependence: effects of scale, host spatial pattern and parasitoid reproductive strategy. Oikos 62:221-230.

Russell, F. L., and S. M. Louda. 2005. Indirect interaction between two native thistles mediated by an invasive exotic floral herbivore. Oecologia 146:373-384.

Settle, W. H., and L. T. Wilson. 1990. Invasion by the variegated leafhopper and biotic interactions: parasitism, competition, and apparent competition. Ecology 71:14611470.

Shaw, R. G., and T. Mitchell-Olds. 1993. ANOVA for unbalanced data: an overview. Ecology 74:1638-1645.

Shurin, J. B., and E. G. Allen. 2001. Effects of competition, predation, and dispersal on species richness at local and regional scales. American Naturalist 158:624-637.

Smith, A. L. 1973. Life cycle of the marsh grass, Scolochloa festucacea. Canadian Journal of Botany 51:1661-1668.

Sokal, R. R., and F. J. Rohlf. 1995. Biometry. Third edition. W. H. Freeman and Company, New York, New York, USA.
Strong, D. R. 1985. Density vagueness: abiding the variance in the demography of real populations. Pages 257-268 in J. Diamond and T. Case, editors. Community ecology. Harper and Row, New York, New York, USA.

Tabachnick, B. G., and L. S. Fidell. 2000. Using multivariate statistics. Allyn and Bacon, Boston, Massachusetts, USA.

Umbanhowar, J., J. Maron, and S. Harrison. 2003. Densitydependent foraging behaviors in a parasitoid lead to densitydependent parasitism of its host. Oecologia 137:123-130.

van der Valk, A. 1989. Northern prairie wetlands. Iowa State University Press, Ames, Iowa, USA.

van Nouhuys, S., and I. Hanski. 2000. Apparent competition between parasitoids mediated by a shared hyperparasitoid. Ecology Letters 3:82-84.

van Veen, F. J. F., R. J. Morris, and H. C. J. Godfray. 2006. Apparent competition, quantitative food webs, and the structure of phytophagous insect communities. Annual Review of Entomology 51:187-208.

Waage, J. K. 1983. Aggregation in field parasitoid populations: foraging time allocation by a population of Diadegma (Hymenoptera, Ichneumonidae). Ecological Entomology $84: 47-453$.

Wiskerke, J. S. C., and L. E. M. Vet. 1994. Foraging for solitarily and gregariously feeding caterpillars: a comparison of two related parasitoid species (Hymenoptera, Braconidae). Journal of Insect Behavior 7:585-603.

Wootton, J. T. 1994. The nature and consequences of indirect effects in ecological communities. Annual Review of Ecology and Systematics 5:443-466.

Zera, A. J. 1984. Differences in survivorship, development rate and fertility between the long-winged and wingless morphs of the waterstrider, Limnoporus canaliculatus. Evolution 38: $1023-1032$.

Zwölfer, H. 1979. Strategies and counterstrategies in insect population systems competing for space and food in flowerheads and plant galls. Fortschritte der Zoologie. 25:331-353.

\section{APPENDIX A}

Statistical results from separate repeated-measures ANOVAs for the effect of planthopper addition/removal treatment on the egg density and parasitism of Delphacodes scolochloa and Prokolisia crocea (Ecological Archives E088-185-A1).

\section{APPENDIX B}

Pearson's product moment correlation matrix for the relationship between Delphacodes scolochloa and Prokolisia crocea egg densities over three generations (Ecological Archives E088-185-A2).

\section{APPENDIX C}

Statistical results from separate analyses for the effects initial density, source of Anagrus and generation on Prokolisia crocea egg density, proportion of eggs parasitized, and likelihood of persistence in experimental cordgrass patches (Ecological Archives E088185-A3). 